\title{
Meatal stenosis: getting the diagnosis right
}

This article was published in the following Dove Press journal:

Research and Reports in Urology

\section{Brian J Morris ${ }^{1,2}$ \\ Stephen Moreton ${ }^{3}$ \\ John N Krieger ${ }^{4}$ \\ 'School of Medical Sciences, University of Sydney, Sydney, NSW, Australia; ${ }^{2}$ Bosch Institute, University of Sydney, Sydney, NSW, Australia; ${ }^{3}$ CircFacts.org, Warrington, UK; ${ }^{4}$ Department of Urology, University of Washington School of Medicine, Seattle, WA, USA}

\section{Dear editor}

Male circumcision is a very common procedure globally. Technical improvements that reduce adverse events are welcome. It has been suggested that meatal stenosis (MS) is a long-term complication of circumcision. Diagnosis of MS is usually based on a change in the elliptical shape of the meatal opening to a circular shape because of fibrosis or scarring, with visually apparent narrowing. There are, however, natural differences in meatal widths in different males, so a narrow meatus does not necessarily indicate functionally significant stenosis.

One school of thought is that MS stems from ischemia of the meatal mucosa stemming from damage to the frenular artery. ${ }^{1,2}$ The only previous evidentiary support for this hypothesis was a conference abstract. ${ }^{3}$ We therefore commend Karami et al ${ }^{4}$ for undertaking a large randomized trial comparing MS prevalence after conventional Plastibell circumcision of newborns with a modified Plastibell technique that leaves the frenulum intact. Their unstated hypothesis would appear to be that use of cautery increases the potential for more tissue reaction and thereby the potential for MS. It should be noted, however, that the Plastibell device is not designed for use with cautery. The use of cautery is an important variable, whether the frenulum is "intact" or not. Cautery results in an electrical injury that may predispose to MS.

A recent study found that MS was absent in boys with "hooded prepuce", a condition in which the glans is completely exposed, leading the authors to conclude that chemical and mechanical traumas are not responsible for MS. ${ }^{5} \mathrm{~A}$ larger study would, however, be needed before drawing such a conclusion.

Participation rate in the study by Karami et al was not disclosed but would have fallen well short of $100 \%$ because written informed consent by parents is never that high. They also do not disclose the percentage of participants lost to follow-up over 16 months, or how this differed between each group. The method of randomization was not disclosed. If different doctors performed different proportions of the two circumcision procedures, then the outcome may be a comparison of different physicians' results rather than a comparison of two procedures. A control group of uncircumcised boys should have been evaluated in the same manner at each time-point of follow-up (as discussed further below). The statistical test used was not disclosed, or whether adjustment was made for multiple comparisons.

They claim that MS prevalence is generally 5-20\%. However, a recent metaanalysis of all studies involving 1.5 million male circumcisions (not cited by Karami
School of Medical Sciences, University of Sydney, Building FI3, Sydney, NSW 2006 Australia

$\mathrm{Tel}+6|2935| 3688$

Fax +6I 2 935I 2227

Email brian.morris@sydney.edu.au 
et al) found a summary risk estimate for MS of $0.656 \%$ (95\% CI 0.435-0.911) and a median prevalence of $0.84 \%{ }^{6}$ This is very much lower than the prevalence of MS reported in Karami et al, which, at 16 months, reached $13.8 \%$ in their conventional Plastibell group and $18.9 \%$ in their Plastibell without frenular ligation group. In attempting to understand the reason for such extraordinarily high MS prevalence values, we note that the authors state "the calibre of the urine stream was estimated by visual inspection". Visual inspection is, however, highly subjective, and the observers were not blinded. When visual inspection only is used, MS cases are more likely to be diagnosed, even when such cases are asymptomatic. Two MS case series have reported MS diagnosis to be incidental in $32 \%$ of $50 \mathrm{MS}$ cases $^{7}$ and in $26.6 \%$ of $120 \mathrm{MS}$ cases. ${ }^{8}$ Most cases were asymptomatic, and obstructive uropathy was not seen.

A recent study of boys circumcised as newborns and diagnosed with MS at age 3-8 years based solely on an upward deflection of the urinary stream and a pinpoint meatus found, using a probe, that the appearance of MS was an "illusion", arising instead from a ventral "meatal web", which was removed by meatoplasty. ${ }^{9}$ It may be that, rather than MS, the diagnoses by Karami et al could comprise mostly of cases of meatal web.

Karami et al reported that the prevalence of MS was $4.9 \%$ and $5.9 \%$ in the conventional and frenular ligation groups, respectively, at 2 months, rising to $8.5 \%$ and $13.7 \%$, respectively, at 12 months and $13.8 \%$ and $18.9 \%$, respectively, at 16 months. ${ }^{4}$ However, a 2017 study monitoring MS onset by repeated visual inspection following neonatal circumcision found that most MS developed in the first 2 months after circumcision, the average time taken being 2.3 and 3.8 weeks in the two groups studied. ${ }^{10}$ Thirty-six (95\%) of the $38 \mathrm{MS}$ cases were asymptomatic.

Karami et al claim that their study was blinded, but this seems unlikely as the presence of an intact frenulum would be apparent during visual inspection.

They state that "MS is extremely rare in boys who are not circumcised" and that "the risk of MS in noncircumcised boys is 10-26 times lower than circumcised boys", citing a Danish study. ${ }^{11}$ However, a critical analysis of data from the latter study showed that the overall MS prevalence in ethnic Danish and other non-Muslim males (uncircumcised) was $0.121 \%$ compared with $0.99 \%$ in Muslim males (circumcised). ${ }^{12}$ MS prevalence as a function of circumcision status became inverted with age in that study: for age 0-9 years, OR for MS was 0.305 in uncircumcised vs. circumcised males, for age 10-19 years,
OR was 0.587 , for age $20-39$ years, OR was 0.619 , for age $40-59$ years, OR was 0.878 , and for age $\geq 60$ years, OR was $1.91 .{ }^{12}$ It should be noted that being uncircumcised can increase MS risk because of the higher risk of penile inflammatory conditions, especially lichen sclerosis, and from urinary tract infections, each of which is more common in uncircumcised males, especially when the uncircumcised male is elderly. Having an uncircumcised group would have allowed them to monitor the higher rate of foreskin-related problems, urinary tract infections, and sepsis among uncircumcised males. Those data would support the net cost-benefit of circumcision, especially because the treatment of asymptomatic MS is likely to have no benefit. In ethnic Danish males, circumcision rate was $0.42 \%$, and there were only four, one, and one MS cases among circumcised males aged $0-9,10-19$, and 20-36 years, respectively. These very small values led the critics to question the reliability of the HRs that were generated in the Danish study. ${ }^{12}$

It is trivial to examine the meatus of the circumcised male. In uncircumcised younger males, nonretractile foreskins are common, ${ }^{13}$ making it difficult to visualize the meatus. A visible meatus was reported in $54 \%,{ }^{14} 53 \%,{ }^{15}$ and $39 \%{ }^{16}$ of uncircumcised male infants and in $47 \%$ of uncircumcised boys under the age of 3 years. ${ }^{17}$ When visual inspection only is used, MS cases are more likely to be diagnosed among circumcised boys, especially where such cases are asymptomatic.

In the absence of a defined objective method for diagnosing MS, the risk of misdiagnosis is high. What is needed is hard data on what constitutes the normal range for meatal diameters in infants and an objective method for measuring these. Visual inspection is unacceptable as a reliable diagnostic method. Karami et al mention "symptomatic presentation" but report no MS symptoms other than subjective meatal narrowing from visual inspection. No mention is made of any of the boys in their study having MS severe enough to merit correction. If a condition causes no symptoms or selfresolves, it is a non-issue clinically. A diagnosis of MS must only be made on the basis of physiological measurements such as urine flow rate, evidence of urinary tract blockage, and kidney function studies.

After taking into account all of the above, we question the validity of the MS diagnoses in the study by Karami et al and suggest that a re-evaluation of their findings and the clinical relevance of their study is warranted. It would seem premature to conclude that "frenulum manipulation" during circumcision is a cause of MS. 


\section{Disclosure}

Brian J Morris is a member of the Circumcision Academy of Australia. Stephen Moreton is the editor of CircFacts.org. The authors report no other conflicts of interest in this communication.

\section{References}

1. Krill AJ, Palmer LS, Palmer JS. Complications of circumcision. Sci World J. 2011;11(2):2458-2468.

2. Persad R, Sharma S, Mctavish J, Imber C, Mouriquand PD. Clinical presentation and pathophysiology of meatal stenosis following circumcision. Br J Urol. 1995;75(1):91-93.

3. Kajbafzadeh A-M, Kajbafzadeh M, Arbab M, Heidari F, Arshadi H, Milani SM. Post circumcision meatal stenosis in the neonates due to meatal devascularisation: a comparison of frenular artery sparing, PlastiBell and conventional technique [abstract No 326]. J Urol. 2011;185(4):e132.

4. Karami H, Abedinzadeh M, Moslemi MK. Assessment of meatal stenosis in neonates undergoing circumcision using Plastibell Device with two different techniques. Res Rep Urol. 2018;10:113-115.

5. Özen MA, Gündoğdu G, Taşdemir M, Eroğlu E. Are mechanical and chemical trauma the reason of meatal stenosis after newborn circumcision? Eur J Pediatr. Epub 2018 Oct 2.

6. Morris BJ, Krieger JN. Does circumcision increase meatal stenosis risk?-A systematic review and meta-analysis. Urology. 2017;110:16-26.

7. Upadhyay V, Hammodat HM, Pease PW. Post circumcision meatal stenosis: 12 years' experience. $N Z$ Med J. 1998;111(1060):57-58.
8. Mahmoudi H. Evaluation of meatal stenosis following neonatal circumcision. Urol J. 2005;2(2):86-88.

9. Özen MA, Gündoğdu G, Taşdemir M, Eroğlu E. Complication of newborn circumcision: Meatal stenosis or meatal web? J Pediatr Urol. 2017;13(6):617.e1-e617.e4.

10. Salimi A, Besharati M, Rashidi Nia S, Shahmoradi S, Eftekhari SS. Application of topical hydrocortisome ointment decreases postcircumcision meatal stenosis in neonates: A cross-sectional study. Int J Pediatr. 2017;5:5061-5067.

11. Frisch M, Simonsen J. Cultural background, non-therapeutic circumcision and the risk of meatal stenosis and other urethral stricture disease: Two nationwide register-based cohort studies in Denmark 1977-2013. Surgeon. 2018;16(2):107-118.

12. Morris BJ, Krieger JN. Re: Cultural background, non-therapeutic circumcision and the risk of meatal stenosis and other urethral stricture disease: Two nationwide register-based cohort studies in Denmark 1977-2013. Surgeon. 2018;16(2):126-129.

13. Mcgregor TB, Pike JG, Leonard MP. Pathologic and physiologic phimosis: approach to the phimotic foreskin. Can Fam Physician. 2007;53(3):445-448.

14. Gairdner D. The fate of the foreskin, a study of circumcision. $\mathrm{Br}$ Med J. 1949;2(4642):1433-1437.

15. Vasudevan G, Manivarmane, Bhat BV, Bhatia BD, Kumar S. Genital standards for south Indian male newborns. Indian $J$ Pediatr. 1995;62(5):593-596.

16. Agarwal A, Mohta A, Anand RK. Preputial retraction in children. $J$ Indian Assoc Pediatr Surgeons. 2005;10:89-91.

17. Dubrovsky AS, Foster BJ, Jednak R, Mok E, McGillivray D. Visibility of the urethral meatus and risk of urinary tract infections in uncircumcised boys. CMAJ. 2012;184(15):E796-E803.

Dove Medical Press encourages responsible, free and frank academic debate. The content of the Research and Reports in Urology 'letters to the editor' section does not necessarily represent the views of Dove Medical Press, its officers, agents, employees, related entities or the Research and Reports in Urology editors. While all reasonable steps have been taken to confirm the content of each letter, Dove Medical Press accepts no liability in respect of the content of any letter, nor is it responsible for the content and accuracy of any letter to the editor.

\section{Publish your work in this journal}

Research and Reports in Urology is an international, peer-reviewed, open access journal publishing original research, reports, editorials, reviews and commentaries on all aspects of adult and pediatric urology in the clinic and laboratory including the following topics: Pathology, pathophysiology of urological disease; Investigation and treatment of urological disease; Pharmacology of drugs used for the treatment of urological disease. The manuscript management system is completely online and includes a very quick and fair peer-review system, which is all easy to use. Visit http://www.dovepress.com/testimonials.php to read real quotes from published authors. 